\title{
A Case of Capecitabine-Related Myelodysplastic Syndrome
}

\author{
Kazunari Anzai $^{1^{*}}$ (D), Masashi Ohe ${ }^{1}$ (D), Haruki Shida ${ }^{1}$ (D), Ken Furuya ${ }^{1}$ (D), \\ Katsuhisa Kogawa ${ }^{2}$
}

${ }^{1}$ Department of Internal Medicine, JCHO Hokkaido Hospital, Japan

${ }^{2}$ Department of Hematology, Sapporo Kyoritsu Gorinbashi Hospital, Japan

Correspondence:

Kazunari Anzai

Address: Department of Internal Medicine, JCHO Hokkaido Hospital, Japan

Email: a244948974@gmail.com
Received: 02.12.2021,

Accepted: 25.12.2021

https://doi.org/10.29333/jcei/11512

Keywords: myelodysplastic syndrome, capecitabine

Dear Editor,

An 81-year-old female patient, who had breast cancer 17 years ago and underwent a mastectomy, subsequently received tegafur/uracil for 3 years. Following which, she again suffered from colorectal cancer 8 years ago and underwent a colectomy. Subsequently, she received eight cycles of capecitabine (CAP) during the half year without any evidence of recurrence. On this occasion, she was referred to our hospital for the further examination of macrocytic anemia during a routine examination. She had no history of neurological problems. She was not a vegetarian. The complete blood count revealed a white blood cell count of 4,190/ $\mu \mathrm{L}$ (basophil, 0.0\%; eosinophil, 1.2\%; neutrophils, $63.5 \%$; lymphocytes, $28.9 \%$; and monocytes, $6.4 \%$ ), hemoglobin ( $\mathrm{Hb}$ ) level of $5.6 \mathrm{~g} / \mathrm{dL}$ with a mean corpuscular volume of $140.5 \mathrm{fL}$ (normal range, 80-99 fL), reticulocyte level of $36.7 \%$ (normal range, $3.0-20.0 \%$ ) and platelet count of $13.5 \times 10^{4}$ $/ \mu \mathrm{L}$. Serological tests revealed direct bilirubin level of $0.37 \mathrm{mg} / \mathrm{dL}$ (normal range, $<0.4 \mathrm{mg} / \mathrm{dL}$ ), lactate dehydrogenase level of 329 U/L (normal range, 124-222 U/L), iron level of $64 \mu \mathrm{g} / \mathrm{dL}$ (normal range, 40-190 $\mu \mathrm{g} / \mathrm{dL}$ ), vitamin $\mathrm{B}_{12}$ level of $139 \mathrm{pg} / \mathrm{mL}$ (normal range, $180-914 \mathrm{pg} / \mathrm{mL}$ ), and folic acid level of $14.1 \mathrm{ng} / \mathrm{mL}$ (normal range, 3.6$12.9 \mathrm{ng} / \mathrm{mL}$ ). The anti-intrinsic factor for pernicious anemia revealed a negative result. A bone marrow aspiration smear revealed a nucleated cell count of $114,000 / \mu \mathrm{L}$ comprising of $1.0 \%$ myeloblasts and a megakaryocyte count of $69.0 / \mu \mathrm{L}$. The cytogenetic analysis revealed no chromosomal abnormalities. The bone marrow aspiration smear revealed a neutrophil with hypersegmentation (Figure 1), a megaloblast (Figure 2A), a bilobulated erythroblast (Figure 2B), an irregularshaped and binucleated erythroblast with Howell-Jolly bodies (Figure 2C), a trinucleated erythroblast (Figure 2D), and a megakaryocyte with separated nuclei (Figure 3). Based on these findings, the patient was diagnosed with vitamin $B_{12}$ deficiency anemia and/or therapy-related myelodysplastic syndrome (MDS), the World Health Organization classification of which was refractory anemia. Concentrated red blood cells were transfused immediately. Hb increased to $9.1 \mathrm{~g} / \mathrm{dL}$. Thereafter, she was treated with intravenous cyanocobalamin. She continued to receive cyanocobalamin; however, $\mathrm{Hb}$ did not increase and remained at approximately $9.0 \mathrm{~g} / \mathrm{dL}$. Considering therapy-related MDS, she received two cycles of DNA-demethylating agent 5azacitidine $\left(75 \mathrm{mg} / \mathrm{m}^{2}\right)$ treatment combined with darbepoetin alfa $(240 \mu \mathrm{g})$ injection once a week. Consequently, $\mathrm{Hb}$ increased and remained at approximately $12.0 \mathrm{~g} / \mathrm{dL}$. Therefore, the cause of macrocytic anemia was thought to be predominantly due to therapy-related MDS because of increased reticulocyte levels, severe erythroblast dysplasia and efficacy of 5-azacitidine and darbepoetin alpfa.

As mentioned above, the present case received tegafur/uracil, and CAP. Three patients who were treated with tegafur or tegafur/uracil, were reported to develop MDS. The median-onset time from initial therapy was 6.7 years [1]. Few studies are reported on the CAP-induced MDS. Tansley et al. reported that a 66-year-old-male patient, who was treated with CAP for 


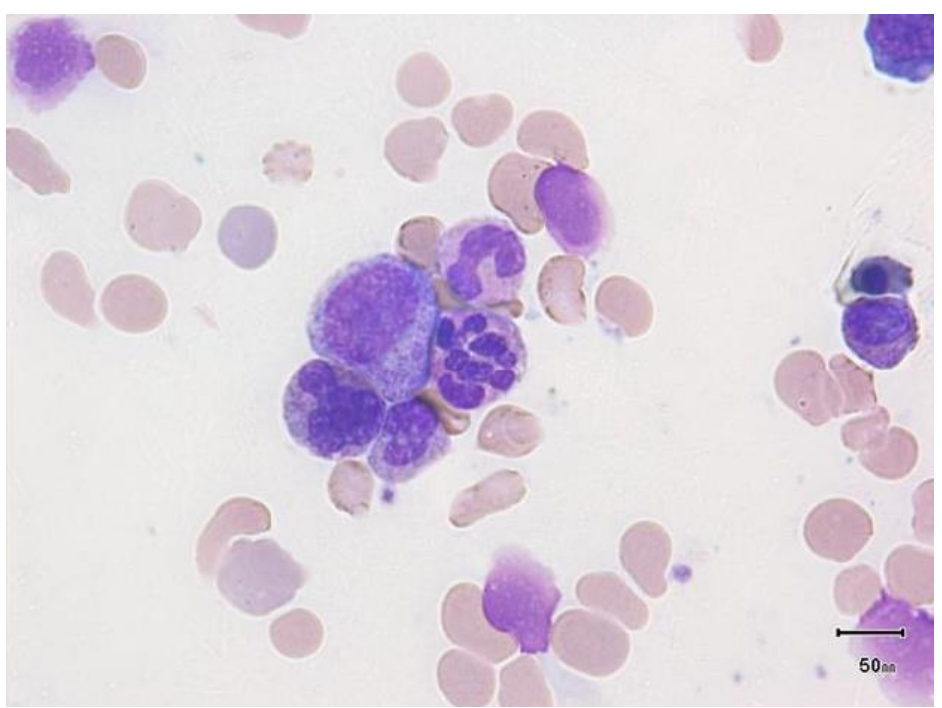

Figure 1. The bone marrow aspiration smear reveals a neutrophil with hypersegmentation

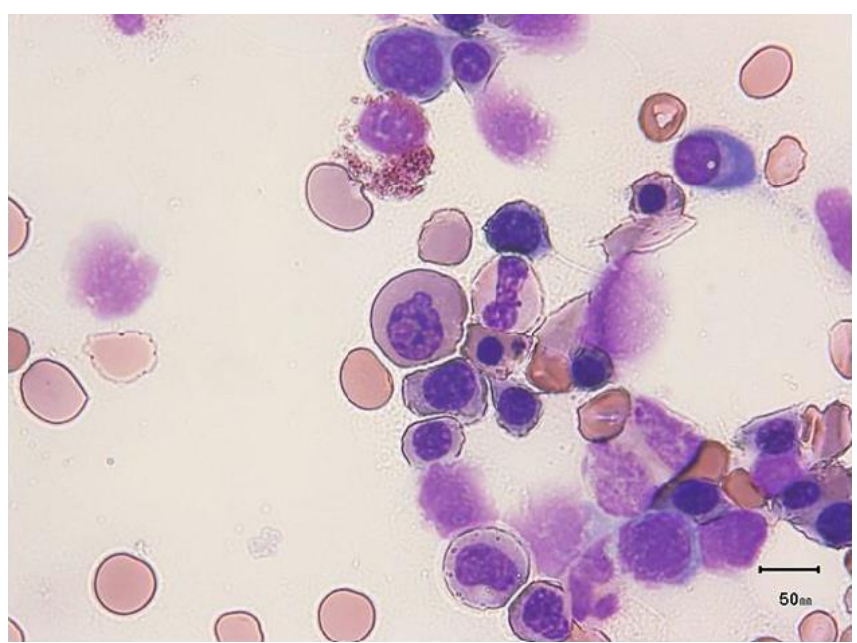

(a)

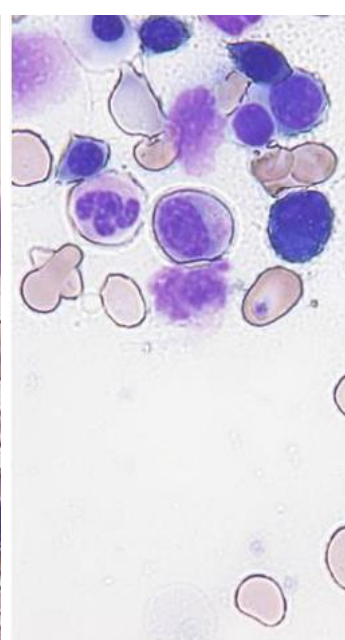

(1)

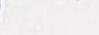

(b)

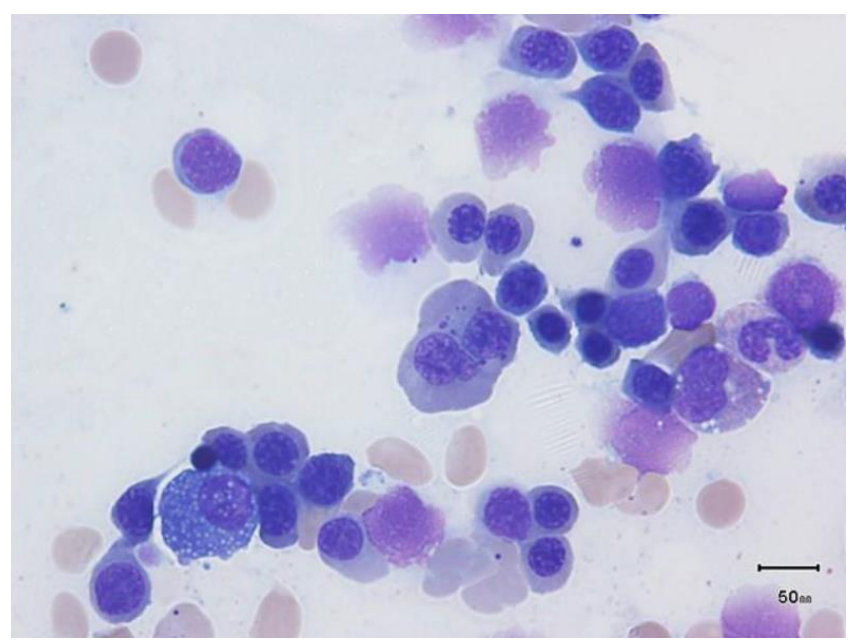

(c)

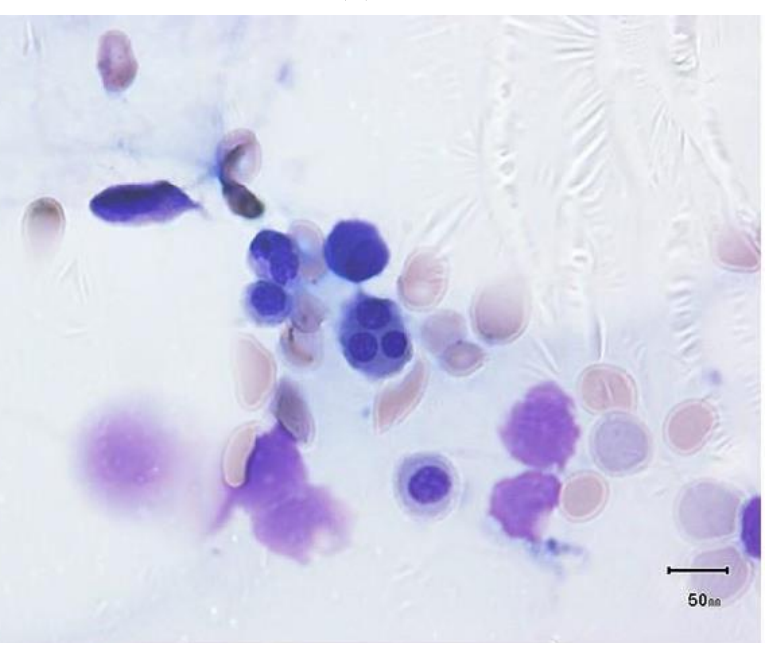

(d)

Figure 2. a) The bone marrow aspiration smear reveals a megaloblast; b) The bone marrow aspiration smear reveals a bilobulated erythroblast; c) The bone marrow aspiration smear reveals an irregular-shaped, binucleated erythroblast with Howell-Jolly bodies; d) The bone marrow aspiration smear reveals a trinucleated erythroblast. 


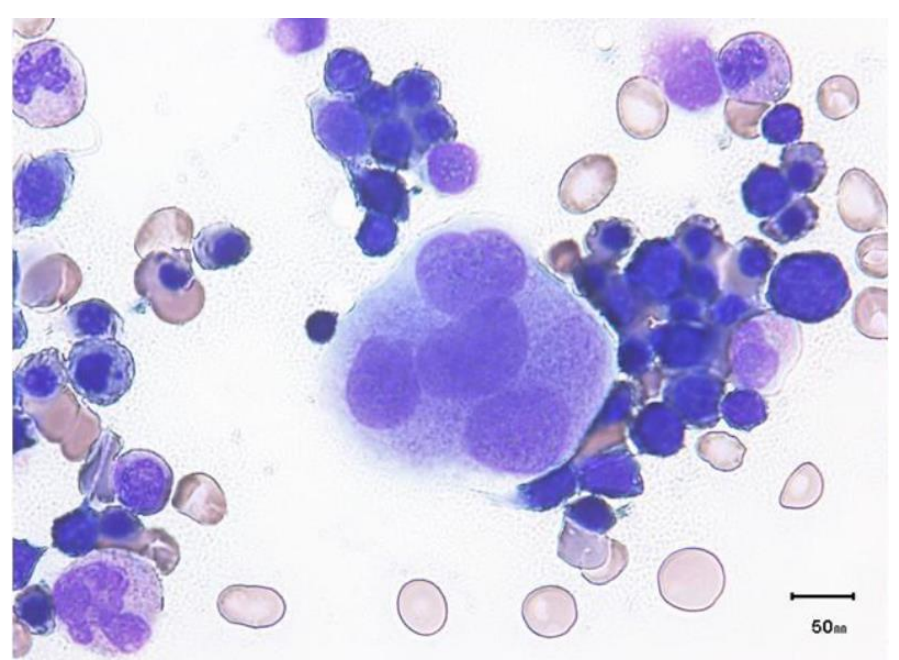

Figure 3. The bone marrow aspiration smear reveals a megakaryocyte with separated nuclei

sigmoid colon cancer after colectomy developed MDS 11 months after CAP treatment [2]. Matsui et al. reported that a 71-year-old-male patient, who was treated with CAP and oxaliplatin, and subsequently CAP and bevacizumab for rectal cancer, developed MDS 3 years after these treatments [3]. Based on these facts, the therapy-related MDS in this case was thought to be due to CAP rather than tegafur/uracil.

Therefore, clinicians should consider CAP-induced MDS because recently, CAP is frequently administered for breast, gastric, and colorectal cancer treatment.

Author contributions: All authors have sufficiently contributed to the study, and agreed with the results and conclusions.

Funding: No funding source is reported for this study.

Declaration of interest: No conflict of interest is declared by authors.

\section{REFERENCES}

1. Abe M, Tanaka Y, Shinohara M, Kosaka M, Matsumoto T. Myelodysplastic syndrome/acute myelogenous leukaemia related to adjuvant chemotherapy with oral pyrimidine anti-metabolites. Br J Haematol. 2000 Nov;111(2):712-3. doi: 10.1046/j.13652141.2000.02357-2.x. PMID: 11122127.

2. Tansley S, Gibbons S. Capecitabine-induced acute myeloid leukaemia. N Z Med J. 2009 May 8;122(1294):118-9. PMID: 19465957.

3. Matsui T, Sakamoto N, Doi A, et al. [Azacitidine for Therapy-Related Myelodysplastic Syndrome Following Oxaliplatin (L-OHP) Therapy for Metastatic Rectal Cancer]. Gan To Kagaku Ryoho. 2018 Aug;45(8):12013. Japanese. PMID: 30158420. 